\title{
Antimicrobial susceptibility pattern of clinical isolates of Pseudomonas aeruginosa isolated from patients of lower respiratory tract infections
}

\author{
Anab Fatima ${ }^{2 *}$, Syed Baqir Naqvi', Sheikh Abdul Khaliq ${ }^{2}$, Shaheen Perveen ${ }^{3}$ and Sabahat Jabeen ${ }^{1}$
}

\begin{abstract}
The present study was conducted to determine the antibiotic susceptibility pattern of Pseudomonas aeruginosa from sputum samples of lower respiratory tract infection patients admitted to different hospitals of Karachi. Most of the hospitals are hampered with high frequency of nosocomial infections generally caused by multiresistant nosocomial pathogen. Among Gram-negative pathogens Pseudomonas aeruginosa considered as most challenging pathogen. The objective of the study was to determine frequency of Pseudomonas aeruginosa from sputum samples and to find out susceptibility pattern against four antibiotics widely used for treatment. The sputum samples from 498 patients were collected consecutively between January 2010 and March 2011 and were cultured and identified. According to CLSI (Clinical Laboratory Standards Institute) guidelines antimicrobial susceptibility testing was performed by disc diffusion method. Pseudomonas aeruginosa were isolated from $24 \%(120 / 498)$ of the lower respiratory tract patient. A higher resistance to Pseudomonas aeruginosa isolate was observed with piperacillin/tazobactam and cefipime i.e. $42 \%$ and $40 \%$ respectively. Imipenem was found to be most effective antibiotic against Pseudomonas aeruginosa (76\% sensitivity) but amikacin resistance was continuously increasing. In conclusion the frequency of Pseudomonas aeruginosa was also higher among lower respiratory tract infection patients with alarmingly high rate of resistance among widely used antibiotics. These findings focused on careful consideration for monitoring and optimization of antimicrobial use in order to reduce occurrence and spread of antimicrobial resistant pathogen.
\end{abstract}

\section{Introduction}

In general practice bronchitis and pneumonia were most common lower respiratory tract infections and were related to considerable mortality and morbidity worldwide (Macfarlane et al. 2001). According to statistics $4.4 \%$ of hospital admissions and $6 \%$ of general practitioner consultations were related to lower respiratory tract infections (Anderson et al. 1993). A wide variety of antimicrobial agents with anti-pseudomonal activity along with advancement in medical and surgical care has been developed but Pseudomonas aeruginosa causing life threatening infections continue to cause complications in hospitals acquired infections (Mayhall 1996). Pseudomonas aeruginosa is a Gram-negative aerobic rod belong to family Pseudomonadaceae. It

\footnotetext{
* Correspondence: anabfatima@hotmail.com

${ }^{2}$ Department of Pharmaceutics, Faculty of Pharmacy, Hamdard University,

Karachi, Pakistan

Full list of author information is available at the end of the article
}

become considered as an opportunistic pathogens and a major cause of nosocomial infections. It was also considered as most challenging pathogen globally because of its high rate of resistance to antimicrobial agents (Hugbo and Olurinola 1992; Trilla 1994). The Pseudomonas aeruginosa had very minimal nutritional requirement that expedited its growth in hospital environment (Gilligan 1995). Resistance to multiple antimicrobial agents displayed by Pseudomonas aeruginosa and only few antibiotics found to be effective against Pseudomonas aeruginosa (Carmeli et al. 1999). A high resistance pattern of Pseudomonas aeruginosa measured as cause of higher mortality rate by Pseudomanal infections (Samporn et al. 2004). Different geographical locations and hospital environments showed variation in susceptibility pattern of Pseudomonas aeruginosa isolates therefore idiosyncrasy of isolate susceptibility pattern 
required for chemotherapeutic approach of Pseudomonal infections for better achievement of results.

In this study we aimed to determine the prevalence of Pseudomonas aeruginosa in lower respiractory tract infection patients and to compare their antibiotic susceptibility pattern.

\section{Materials and Methods Study setting}

A total number of 498 sputum samples were collected from adult patients attended/admitted in pulmonary department of various hospitals and clinics suffered from lower respiratory tract infections in 14 months period from January 2010 to March 2011. Out of 498 samples 120 samples were Pseudomonas aeruginosa.

\section{Microbiology/sample processing}

The samples were transferred to microbiology laboratory and were analyzed within $30 \mathrm{~min}$ to 1 hour of collection. Nutrient agar, MacConkey agar and blood agar (Oxoid UK) used for streaking of sample and then incubated at $37^{\circ} \mathrm{C}$ for 24 hours as described by chessborough (Cheesborough 2002). After incubation Pseudomonas isolation agar media (Oxoid UK) used for sub-culturing of isolate obtained. The pure isolates of Pseudomonas aeruginosa were transferred to $1 \%$ nutrient agar slant and stored in the refrigerator at $4 \pm 1^{\circ} \mathrm{C}$. Diifferent identification tests were performed on suspected Pseudomonas aeruginosa and were characterized and identified i.e. Gram-stain, colonial morphology, positive oxidase reaction, production of pyocyanin on Mueller-Hinton agar (Oxoid UK), citrate utilization and growth at $42^{\circ} \mathrm{C}$.

\section{Antibiotic susceptibility test}

By disk diffusion technique antibiotic susceptibility pattern of isolates on commonly used antibiotics was performed on Mueller-Hinton agar medium according to Clinical Laboratory Standard Institute (CLSI) guidelines (NCCLS 1995). Paper disk were impregnated with antibiotics (Sigma chemicals): imipenem $(10 \mu \mathrm{g})$, Amikacin $(30 \mu \mathrm{g})$, piperacillin / tazobactam $(100 / 10 \mu \mathrm{g})$ and cefipime $(30 \mu \mathrm{g})$ respectively and incubated at $37^{\circ} \mathrm{C}$ for 24 hours in $5-10 \% \mathrm{CO}_{2}$ enriched environment. The medium containing antibiotic disks were quality controlled daily by standard culture. After defined incubation period the diameter of zone of inhibition was measured and interpretation of result based on CLSI guidelines was performed (NCCLS 1995).

\section{Result}

In 14 months period a total of 498 sputum specimens were collected consecutively from different hospitals of Karachi and a total of 120 Pseudomonas aeruginosa strains (24\%) were isolated of which 85 samples (70.8\%) and 35 samples $(29.1 \%)$ were reported from males and females respectively (Figure 1).

The antibiotic resistance pattern of isolates presented in Figure 2. The most effective antibiotic was from Carbapenem i.e. imipenem and its resistance rate was detected as $24 \%$.

Piperacillin/tazobactam and cefipime showed more resistance i.e. $42 \%$ and $40 \%$ respectively. Amikacin also showed 35\% resistance. Graphically Figure 2 clearly reflect antibiotic susceptibility profile of Pseudomonas aeruginosa isolates and showed that imipenem was most sensitive then all other antibiotics used.

\section{Discussion}

The main objective of this study was to investigate epidemiological data of Pseudomonas aeruginosa strains in lower respiratory tract infection patients and to determine the antimicrobial resistance pattern of bacteria against some commonly used antibiotics. The predominance of Pseudomonas aeruginosa resistance considered as serious problem in many countries (Agarwal et al. 2006; Ako-Nai et al. 2006; Balkhy et al. 2006; Lizioli et al. 2003). It was also reported that Pseudomonas aeruginosa is one of the most common nosocomial pathogen and a leading cause of nosocomial respiratory tract infection (Gilligan 1995; Jarvis and Martone 1992; Jarlier et al. 1996).

From previous literature high rate of resistance against carbapenem, quinolones and third generation cephalosporin had been detected in Pseudomonas aeruginosa (Hancock 1998; Quinn 1998; Sader et al. 1998). In our study resistance rate against imipenem from carbapenem group was determined as $24 \%$ which was considerably accelerating towards higher side in Pakistan and this was in agreement with previous study conducted by Akhtar $\mathrm{N}$ which showed resistance rate of 26.1\% (Akhtar 2010). It was reported that resistance to imipenem was $14 \%$ in Spain (Bouza et al. 1999), 19.3\% in Italy (Bonfiglio et al. 1998) and was 68\% in Saudi Arabia (Rotimi et al. 1998).

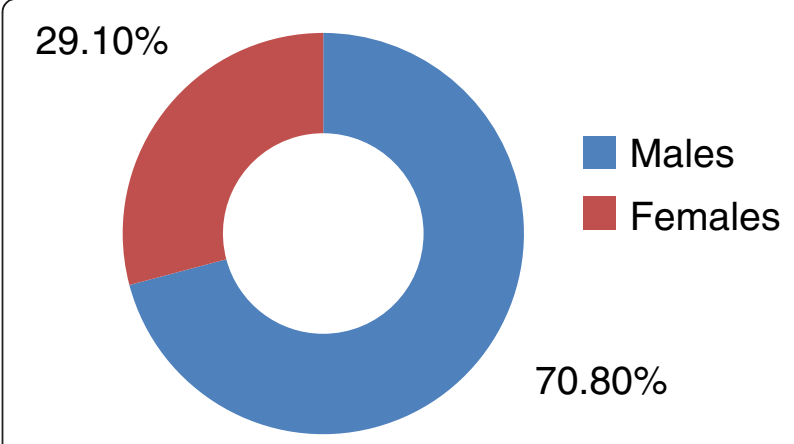

Figure $1 \%$ occurrence of lower respiratory tract infections in males and females by Pseudomonas aeruginosa. 


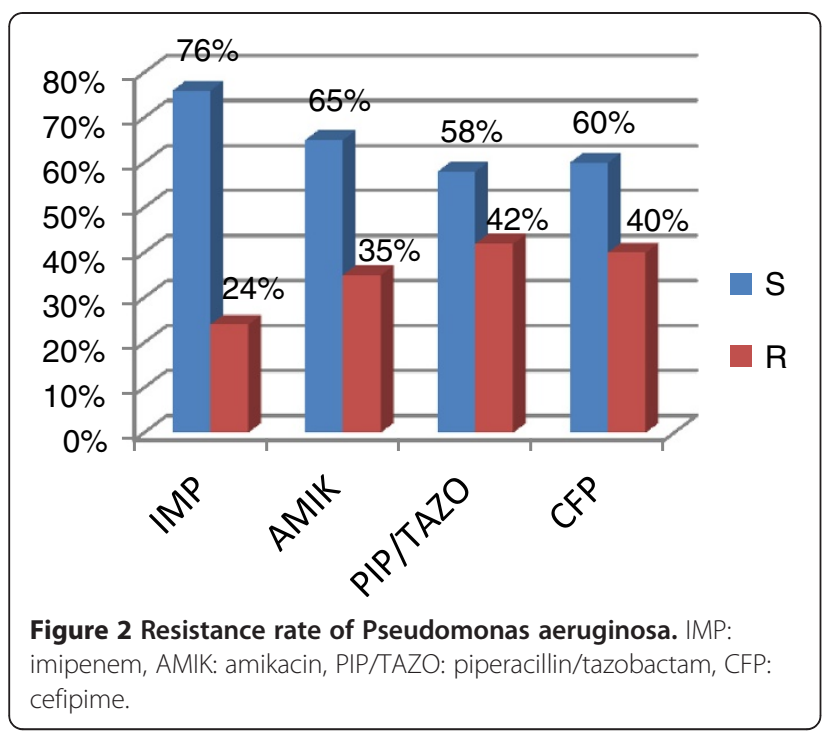

In a previous hospital study resistance rate among Pseudomonas aeruginosa was only 5-9\% against amikacin (Bouza et al. 1999; Gerding et al. 1991). In the present study the rate of amikacin resistance was found to be relatively high i.e. $35 \%$ however it may in accordance with Friedland et al. who reported that amikacin resistance related to more intensive usage of amino glycosides (Friedland et al. 1992). The increasing rate of amikacin in Pakistan was also reported by Akhtar $\mathrm{N}$ i.e. 21.3 against Pseudomonas aeruginosa (Akhtar 2010). It was further investigated that when amikacin used in combination with impenem i.e. as combination therapy resistance rate among Pseudomonas aeruginosa was reduced to $10 \%$ (Bustamante et al. 1987).

Piperacillin/tazobactam resistance rate was $7 \%$ in a nationwide in Spain (Bouza et al. 1999). Contrary to this resistance rate in isolates was higher in our study (42\%). In a previous study equivalent safety and efficacy of intravenous Piperacillin/tazobactam with intravenous imipenem/cilastatin was reported for intra-abdominal infections caused by Pseudomonas aeruginosa but presently resistance was different for both antibiotics which might be due to extensive usage of this combination in our hospitals as life saving antibiotics (Erasmo et al. 2004).

In the present study resistance rate of Pseudomonas aeruginosa against cefepime observed was deviated from reported data as it showed $40 \%$ resistance while in previous reported data it did not exceed 17\% (Bouza et al. 1999).

The data obtained from our study in Pakistan it was probable that application of conventional agents for the empirical treatment become complicated by the respiratory pathogens with accelerating resistance to antibiotics. Therefore for an effective management of lower respiratory tract infection an ultimate and detailed bacteriological diagnosis and susceptibility testing required to overcome global problem of antibiotic resistance and by encouraging greater understanding of this problem different solutions can be planned by health care providers.

\section{Competing interests}

The authors declare that they have no competing interests.

\section{Authors' contributions}

AF: carried out main research work as she was research fellow. SBN: He was research supervisor, performed continuous vigilance via out research work. SAK: Involved in searching and validation of method. SP: Carried out data compilation, did drafting of manuscript. SJ: She did verification and identification of clinical isolates. All authors read and approved the final manuscript.

\section{Author details}

${ }^{1}$ Department of Pharmaceutics, Faculty of Pharmacy, University of Karachi, Karachi, Pakistan. ${ }^{2}$ Department of Pharmaceutics, Faculty of Pharmacy, Hamdard University, Karachi, Pakistan. ${ }^{3}$ Department of Pharmaceutics, Faculty of Pharmacy, Jinnah University for Women, Karachi, Pakistan.

Received: 18 October 2012 Accepted: 6 December 2012

Published: 18 December 2012

\section{References}

Agarwal R, Gupta D, Ray P (2006) Epidemiology, risk factors and outcome of nosocomial infections in a respiratory intensive care unit in north India. J Infect 53(2):98-105

Akhtar N (2010) Hospital acquired infections in a medical intensive care unit. J Coll Physicians Surg Pak 20(6):386-390

Ako-Nai AK, Ikem IC, Akinloye OO, Aboderin AO, Ikem RT, Kassim OO (2006) Characterization of bacterial isolates from diabetic foot infections in lle-lfe, south western Nigeria. Foot 16(3):158-164

Anderson H, Esmail A, Hollowell J, Littlejohns P, Strachen D (1993) Epidemiologically based needs assessment: lower respiratory disease. DHA Project Research Programme, Government publication Publisher: NHS Management Executive, 1993.report 16, pp 6-12

Balkhy HH, Cunningham G, Chew FK (2006) Hospital- and community-acquired infections: a point prevalence and risk factors survey in a tertiary care center in Saudi Arabia. Int J Infect Dis 10(4):326-333

Bonfiglio G, Carciotto V, Russo G et al (1998) Antibiotic resistance in pseudomonas aeruginosa: an Italian survey. Antimicrob Chemother 41:307310

Bouza E, Garcia-Gorrote F, Cercenado E, Marin M, Diaz MS (1999) Pseudomonas aeruginosa: a survey of resistance in 136 hospitals in Spain. The Spanish pseudomonas aeruginosa study group antimicrob agents chemother, 43rd edn., pp 981-982

Bustamante Cl, Drusano Gl, Wharton RC, Whade GC (1987) Synergism of the combinations of imipenem plus ciprofloxacin and imipenem plus Amikacin against pseudomonas aeruginosa and other bacterial pathogens. Antimicrob Agents Chemother 31(4):632-634

Carmeli Y, Troillet N, Eliopoulos GM, Samore MH (1999) Emergence of antibioticresistant pseudomonas aeruginosa: comparison of risks associated with different anti pseudomonal agents. Antimicrob Agents Chemother 43:13791382

Cheesborough M (2002) Medical laboratories manual for trocountries. Tropical Health Technol. Butterworth London 2:479

Erasmo AA, Crisostomo AC et al (2004) Randomized comparison of piperacillin/ tazobactam versus imipenem/cilastatin in the treatment of patients with intra-abdominal infections. Asian J Surg 27(3):227-235

Friedland IR, Funk E, Khoosal M, Klugman KP (1992) Increased resistance to Amikacin in a neonatal unit following intensive Amikacin usage. Antimicrob Agents Chemother 36(8):1596-1600

Gerding DN, Larson TA, Hughes RA et al (1991) Amino glycoside resistance and amino glycoside usage: ten years of experience in one hospital. Antimicrob Agents Chemother 35(7):1284-1290 
Gilligan PH (1995) Pseudomonas and Burkholderia. In: Murray RR, Baron EJ, Pfaler MA, Tenover FC, Yolken RH (eds) Manual of clinical microbiology. American Society for Microbiology, Washington DC, pp 509-519

Hancock REW (1998) Resistance mechanism in pseudomonas aeruginosa and other nonfermentative gram-negative bacteria. Clin Infect Dis 27:289-299

Hugbo PG, Olurinola PF (1992) Resistance of pseudomonas aeruginosa to antimicrobial agents: implications in medicine and pharmacy. Nig J Pharm Sci 4:1-10

Jarlier V, Fosse T, Philippon A (1996) Antibiotic susceptibility in aerobic gramnegative bacilli isolated in intensive care units in 39 French teaching hospitals (ICU study). Intensive Care Med 22:1057-1065

Jarvis WR, Martone WJ (1992) Predominant pathogens in hospital infections. J Antimicrob Chemother 29(A):19-24

Lizioli A, Privitera G, Alliata E (2003) Prevalence of nosocomial infections in Italy: result from the Lombardy survey in (2000). J Hosp Infect 54(2):141-148

Macfarlane J, Holmes W, Gard P, Macfarlane R, Rose D, Weston V, Leinonen M, Saikku P, Myint S (2001) Prospective study of the incidence, aetiology and outcome of adult lower respiratory tract illness in the community. Thorax 56 (2):109-114

Mayhall CG (1996) Nosocomial burn wound infection. In: Mayhall GC (ed) Hospital epidemiology and infection control. William and Wilkins Co, Baltimore, MD, USA, pp 225-236

National Committee for Clinical Laboratory Standards (1995) Approved standard M2 A7 NCCLS. In: Villanova PA (ed) Performance standards for antimicrobial disk susceptibility tests., p 15, NCCLS T 940 West Valley Road T Suite 1400 T Wayne, PA 19087 T USA, T PHONE 610.688.0100

Quinn JP (1998) Clinical problems posed by multiresistant nonfermenting gramnegative pathogens. Clin Infect Dis 27:117-124

Rotimi VO, Al-Sweih NA, Feteih J (1998) The prevalence and antibiotic susceptibility pattern of gram-Negative bacterial isolates in two ICUs in Saudi Arabia and Kuwait. Diagn Microbiol Infect Dis 30:53-59

Sader HS, Jones RN, Gales AC et al (1998) Antimicrobial susceptibility patterns for pathogens isolated from patients in Latin American medical centers with a diagnosis of pneumonia: analysis of results from the SENTRY antimicrobial surveillance program (1997). SENTRY Latin American study group. Diagn Microbiol Infect Dis 32:289-301

Samporn S, Chuntima T, Thitiya Y, Chertask D (2004) Prevalence and antimicrobia susceptibility of pseudomonas aeruginosa mucoid and non-mucoid type. SE Asian J Trop Med 35:893-894

Trilla A (1994) Epidemiology of nosocomial infections in adult in care units. Intensive Care Med 20(3):1-4, 1

doi:10.1186/2193-1801-1-70

Cite this article as: Fatima et al:: Antimicrobial susceptibility pattern of clinical isolates of Pseudomonas aeruginosa isolated from patients of lower respiratory tract infections. SpringerPlus 2012 1:70.

\section{Submit your manuscript to a SpringerOpen ${ }^{\circ}$ journal and benefit from:}

- Convenient online submission

- Rigorous peer review

- Immediate publication on acceptance

- Open access: articles freely available online

- High visibility within the field

- Retaining the copyright to your article

Submit your next manuscript at $>$ springeropen.com 